\title{
Analysis of the running-in of thermal spray coatings by time-dependent stribeck maps
}

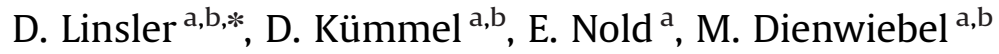 \\ ${ }^{a}$ Fraunhofer Institute for Mechanics of Materials IWM, MicroTribology Center $\mu$ TC, Rintheimer Querallee 2a, 76131 Karlsruhe \\ ${ }^{\mathrm{b}}$ Karlsruhe Institute of Technology KIT, Institute for Applied Materials IAM, Kaiserstr. 12, 76131 Karlsruhe, Germany
}

Keywords:

Lubricated sliding wear

Thermal spray coatings

Running-in behavior

Tribochemistry

\begin{abstract}
A B S T R A C T
As thermal spray coated cylinder surfaces eliminate the need for cast iron sleeves or hypereutectic AlSi alloys, these coatings are becoming the main cylinder liner technology. Moreover, it has been found that these coatings also lead to low friction and wear. The reason for improved tribological performance is believed to result from a nanocrystalline layer that forms in the sliding contact. In this paper, we use on line wear measurement to study the dynamics of the running in process. A pin on disk tribometer coupled to a radionuclide wear measurement (RNT) system was used to investigate the friction and wear behavior of wire arc spray (LDS) coatings sliding against chromium coatings under lubricated conditions. After the friction experiments, X ray photo electron spectroscopy (XPS) and Focused Ion Beam analysis (FIB) was used to characterize the worn surfaces. By introducing a time dependent Stribeck plot, we analyzed running in under constant and transient sliding conditions and observed a strong reduction of friction in the boundary lubrication regime. Wear rates of the LDS disks as well as of the chromium plated pins are ultra low. XPS revealed carbon diffusion at room temperature in wear tracks of disks that showed a very low coefficient of friction ( $\mathrm{CoF}$ ) of 0.01 , whereas this carbon diffusion could not be de tected in the wear track of a disk without running in, i.e. a final CoF of 0.12 . As this is the most significant difference found between differently run in systems, the described carbon diffusion might be relevant for the observed friction behaviour. Running in behaviour can only be discussed in terms of friction, as, even with RNT, no significant wear could be measured. The comparison of running in under transient and constant conditions showed only minor differences in the final friction behavior.
\end{abstract}

\section{Introduction}

A higher power density in combustion engines due to downsizing and turbocharging leads to harsher environments that challenge the durability of conventional AISi liner surfaces in terms of wear. In re cent years, thermal spray iron coatings have been used to improve the wear behavior of cylinder bore surfaces [1,2].

In order to further improve the tribological behavior of these iron based coatings, it is necessary to understand the fundamental mechanics and dynamics in these systems that lead to superior friction and wear. If a model system is operated with comparable wear rates and with materials that are also used in the real system, the understanding of friction and wear mechanisms in the model system is a first step for defined adaptions of the real system [3]. In the present case, a pin on disk tribometer is used as a model

\footnotetext{
* Corresponding author at: Fraunhofer Institute for Mechanics of Materials IWM, MicroTribology Center $\mu \mathrm{TC}$, Rintheimer Querallee 2a, 76131 Karlsruhe.

E-mail address: dominic.linsler@iwm.fraunhofer.de (D. Linsler).
}

system. Industry standard piston rings are nitrided or coated, e.g. with chromium. This is why, in the present work, the tribological system of a chromium coated pin against a thermal spray coated, ground disk is used.

Publications in the field of thermal spray coatings also deal with mechanical or tribological stability of thermal sprayed layers. Rabiei et al. [4] identify the crack propagation in amorphous oxide layers between the splats, and also Milanti et al. [5] find a lower microhardness for coatings with slightly defected particle boundaries. The work of Hahn and Fischer et al. $[6,3,1]$ is con cerned with microstructural and chemical alterations at the sur face, describing the impact of alloy modification on the tribological behavior of the coatings. To the knowledge of the authors, there is no publication explicitly considering the running in behavior of thermal spray coatings so far.

To fulfill engine life times of several thousand hours, wear rates of bearings and liners have to be in the ultra low wear regime with a few nanometers per hour. In many cases, wear rates in the ultra low wear regime are connected with a running in behavior, 
that usually entails a decrease in friction as well as in the wear rate $[7,8]$. It has been shown for several tribological systems, that running in behavior strongly depends on the load and speed conditions. Considering pin on disk experiments, many published results are measured at load and speed conditions, that are con stant until a constant wear rate or friction is measured $[9,10,8,11]$. The present paper addresses the question, if there is an influence of a dynamic load and speed variation during the running in on the final friction value and the system wear rate. Moreover, mi crostructure and chemical composition of worn surfaces are ana lyzed to understand the mechanisms leading to differences in friction behavior.

\section{Materials and methods}

\subsection{Materials}

\subsubsection{Disks}

Grey cast iron disks (ASTM A48: NO.30, EN GJL 200) have been roughened with a high pressure water jet (Hammelmann, Oelde, Germany) and coated with a thermally sprayed layer (Fe $0.9 \mathrm{wt} \%$ C, Daimler AG, Germany) with a thickness of approx. $500 \mu \mathrm{m}$. SEM images of metallographic sections show the characteristic splats and pores of a thermal spray coating (see Fig. 1(b)). The porosity of the coating is $3 \%$. As a final machining step, the disks have been grinded to a roughness $R_{a}$ of $0.43 \mu \mathrm{m}$. Focused ion beam (FIB) cross sections in the machined, unworn surface show a grain refined layer up to a depth of approx. one $\mu$ m due to the final machining.

\subsection{2. pins}

Steel pins (Fe $0.85 \mathrm{wt} \% \mathrm{C}$ ) have been coated with a galvanic chromium layer (Federal Mogul, Burscheid, Germany; "Goetze Diamond coating" (GDC)). After coating, the pins were grinded and lapped to a final thickness of $100 \mu \mathrm{m}$. In FIB cross sections, the unworn pins show a submicrocrystalline microstructure. Changes of microstructure due to final machining could not be imaged. XPS measurements on the unworn pins revealed an increased oxygen

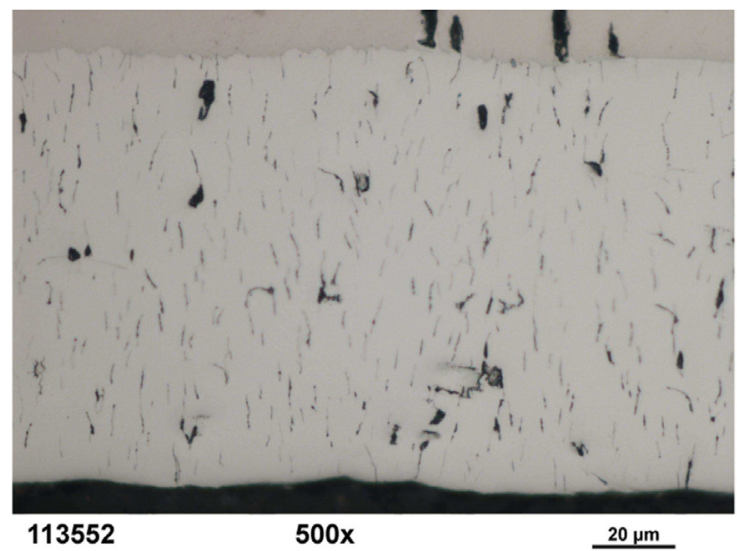

(a) Light microscopic image of metallographic cross section of the chromium coating on the pin. Black lines in the coating are the cracks as described in the text. content of up to 40 at \% in the first $200 \mathrm{~nm}$ depth and a varying carbon concentration from 2 to 25 at \%. This is due to the de position process, where alternate layers of chromium and, ac cording to the manufacturer, diamond is deposited. The diamond agglomerates in pores or cracks of the chromium layer according to the producer of the layers [12]. XPS measurements revealed that the diamond, that is deposited, partially consists of carbides. The carbide content varies with sputter depth and measurement po sition from 15 to $60 \%$. A light microscope image of an unworn pin is shown in Fig. 1(a).

\subsubsection{Oil}

The oil used for all pin on disk experiments was fully for mulated engine oil Castrol Edge FST 5W30 at a temperature of $80^{\circ} \mathrm{C}$. The oil circuit was filled with 2.5 liters. Using a nozzle, oil was directly supplied to the disk.

\subsection{Methods}

\subsubsection{Tribometer}

All measurements were performed on a pin on disk tribometer "Basalt" produced by Tetra (Tetra Ilmenau, Germany) with a cus tomized software and force sensor equipped with strain gauges. Resolution of the force sensor was $1 \mathrm{~N}$, which yields an error for the measurement of the friction coefficient of 0.02 for the lowest pressure of $2.5 \mathrm{MPa}$.

\subsubsection{Radionuclide technique}

When measuring wear with the radionuclide technique (RNT), one or both samples being in tribological contact are slightly radioactively marked so that also wear debris is radioactive. The activity in the oil is measured and correlated to the wear particle weight using a reference sample of known mass. Advantages of the method are the high resolution of 0.1 micrograms of wear per hour and online wear measurement [9]. To obtain radiotracers, pins were subjected to low energy neutron radiation at FRM II in Munich. The oil circuit of the tribometer was connected to a gamma detector (Zyklotron AG, Leopoldshafen, Germany) allowing

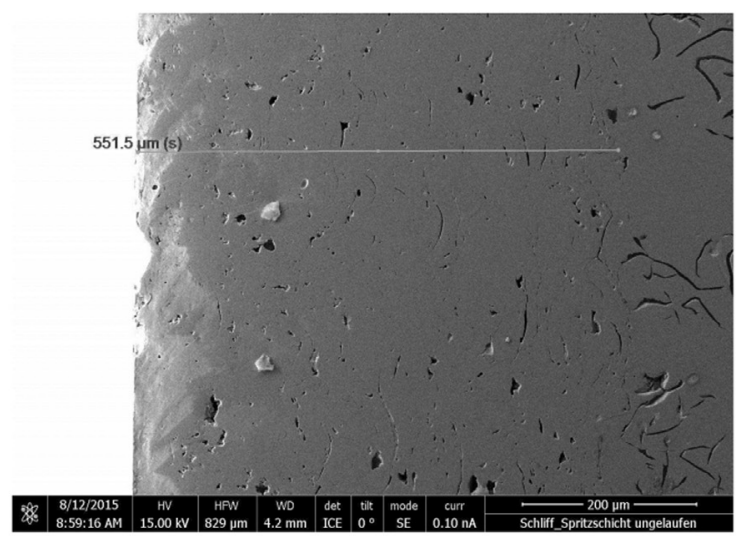

(b) Electron microscopic image of a cross section of the unworn thermal spray coating.

Fig. 1. Images of metallograhpic cross sections of the unworn coatings of pin and disk. 
continuous monitoring of wear in the oil. $\mathrm{Cr} 51$ was used as tracer nuclide. To account for decay effects, a reference measuring device was used. The accuracy of $0.1 \mu \mathrm{g} / \mathrm{h}$ corresponds to a pin wear of $1 \mathrm{~nm} / \mathrm{h}$, when considering the pin diameter and the density of $\mathrm{Cr}$.

\subsubsection{Focused ion beam}

Focused Ion Beam (FIB) cross sections were done using a FEI Helios 650 Dual Beam instrument (FEI, Hillsboro, Oregon, USA). Ion beam assisted deposition of a platinum containing protective layer was used to protect the surface from ion beam damage at high currents while doing the cross sectioning.

\subsubsection{Topography analysis}

Topography was measured using a Sensofar $\mathrm{Pl} \mu 2300$ white light interferometer (Sensofar, Barcelona, Spain). Ex situ wear rate was determined by measuring the topography on a line perpendicular to and longer than the wear track width, so that wear track depth could be assessed. The pin wear was only measured with RNT, as the loss of pin height of less than a micron as indicated by RNT measurements could not be measured by methods available to the authors.

\subsubsection{XPS}

$\mathrm{X}$ ray photoelectron spectroscopy (XPS) depth profiles were recorded with a PHI 5000 Versaprobe system with $15 \mathrm{keV}$ mono chromatic $\mathrm{Al} \mathrm{K} \alpha \mathrm{x}$ ray excitation and an energy resolution of $0.2 \mathrm{eV}$. Argon ions were used for material removal for depth pro filing. The sputter rate was determined by means of a silicon oxide reference. The area exposed to argon ions was about $2 \times 2 \mathrm{~mm}^{2}$. Photoelectrons were excited from an area of $200 \times 300 \mu \mathrm{m}^{2}$ so that sample inhomogeneities do not have to be considered.

\section{Results}

\subsection{Experimental design}

Besides friction and wear, it was shown by Scherge et al. [13 15], that sensitivity is an important criterion for the evaluation of a tribosystem. Scherge et al. [9] showed, that the constant wear rate after running in can depend on the initial load the tribosystem is subjected to. This means, that different initial or running in con ditions can yield a different tribological behavior in terms of fric tion and wear. For the comparison of friction after a running in, it is necessary to measure the friction under comparable conditions. This is the reason why, in the present paper, for the comparison of tribosystems that are run in at different pressures and speeds, a testing sequence with a constant pressure of $15 \mathrm{MPa}$ and speeds that cover the mixed lubrication regime is run at the end of each experiment. The comparison of these in the following called "Stribeck curves" allows an assessment of the influence of the chosen initial parameters on the friction behavior after the run ning in.

As mentioned above, (initial) loading conditions can alter the friction and wear behavior of a tribosystem. The goal of the pre sent set of experiments was to study the tribological behavior of a pairing of a modern liner material (thermal spray coating) against a typical piston ring material (Chromium coating) on a model setup of a pin on disk machine. In an engine, the piston ring is subjected to a speed variation from zero to several meters per second. In addition, the loads change due to compression and ignition. To approach this change of loads and speeds and to find if there is an effect of these parameters on the running in behavior, the following experimental setup was tested:

- constant load and speed

- constant load and changes in speed
- constant speed and changes in load.

In the case of constant load and speed, the test is performed with constant pressure and speed for a sliding distance of $220 \mathrm{~km}$, continued with the measurement of five stribeck curves at a pressure of $15 \mathrm{MPa}$ and speeds of $0.1,0.2,0.3,0.4,0.5,0.75,1,1.5$, 2 and $2.5 \mathrm{~m} / \mathrm{s}$ and a duration of $1 \mathrm{~min}$ for each speed.

This range of speeds is also used in the transient experiments with a constant pressure. Pressures of 15 and $35 \mathrm{MPa}$ have been tested. The overall sliding distance was $200 \mathrm{~km}$ for this kind of experiment and during the test, 360 stribeck curves were mea sured. Independent of the test load, also this kind of experiment was finished with a set of stribeck curves measured at a pressure of $15 \mathrm{MPa}$.

For the transient test program with constant speed, friction was measured at speeds of $1 \mathrm{~m} / \mathrm{s}$ and $0.33 \mathrm{~m} / \mathrm{s}$ with pressures of 2.5 , $7.5,15,25,35$ and $45 \mathrm{MPa}$. The overall sliding distance was $225 \mathrm{~km}$. As in the previous cases, the described set of stribeck curves at $15 \mathrm{MPa}$ was measured at the end of each experiment. An overview of the different pressures and speeds in the test pro grams is given in Table 1.

\subsection{Wear results}

Eight of in total 15 pin on disk experiments were carried out using radioactively labeled pins and RNT as described above. Pin wear rates of less than $0.1 \mu \mathrm{g}$ per hour were found, which is the resolution limit of the method. Fig. 2 shows an exemplary result of the RNT measurement.

The measurement of the disk wear tracks after the experiment showed wear track depth that yield an average wear rate of less than $10 \mathrm{~nm}$ per $\mathrm{h}$. Due to roughness and depth inhomogeneities, no accurate trend of wear in the different experiments can be determined. As for the pin wear, all disk wear was ultra low and comparable. On pin and disk, grinding marks were still visible after the test, indicating that there was only little amount of wear.

\subsection{Friction results}

\subsubsection{Constant load and speed}

Fig. 3(a) shows the coefficient of friction (CoF) over the sliding distance for experiments at different loads and speeds. For two of the experiments, a pronounced running in, i.e. a decrease of the CoF over time was observed. The experiments at $35 \mathrm{MPa}$ and $2 \mathrm{~m} / \mathrm{s}$ (CoF approx 0.12) and $15 \mathrm{MPa}$ and $1 \mathrm{~m} / \mathrm{s}$ (CoF approx 0.02) didn't show a decrease in $\mathrm{CoF}$ during the experiment,but a pronounced difference in the CoF.

For the comparison of the friction behavior, the stribeck curves measured at $15 \mathrm{MPa}$ after each experiment with constant load are plotted in Fig. 3(b). Whereas the values for low speeds of $0.1 \mathrm{~m} / \mathrm{s}$ hardly differ, there is a significant difference in the CoF for higher speeds. The three curves after run in at $1 \mathrm{~m} / \mathrm{s}$ are in elasto hydrodynamic regime (friction drops because of the in creased amount of lubricant between pin and disk due to the

Table 1

Description of pressures and speeds in the different test programs.

\begin{tabular}{ll}
\hline Constant pressure and speed & \\
$15 \mathrm{MPa}, 1 \mathrm{~m} / \mathrm{s} ; 35 \mathrm{MPa}, 1 \mathrm{~m} / \mathrm{s}, 35 \mathrm{MPa}, 2 \mathrm{~m} / \mathrm{s}$ & \\
Constant pressure and transient speed & \\
$15 \mathrm{MPa}$ & $0.1,0.2, \ldots, 0.5,0.75,1,2,2.5 \mathrm{~m} / \mathrm{s}$ \\
$35 \mathrm{MPa}$ & $0.1,0.2, \ldots, 0.5,0.75,1,2,2.5 \mathrm{~m} / \mathrm{s}$ \\
& \\
Constant speed and transient pressure & $0.33 \mathrm{~m} / \mathrm{s}$ \\
$2.5,7.5,15,25,35,45 \mathrm{MPa}$ & $1 \mathrm{~m} / \mathrm{s}$ \\
$2.5,7.5,15,25,35,45 \mathrm{MPa}$ & \\
\hline
\end{tabular}




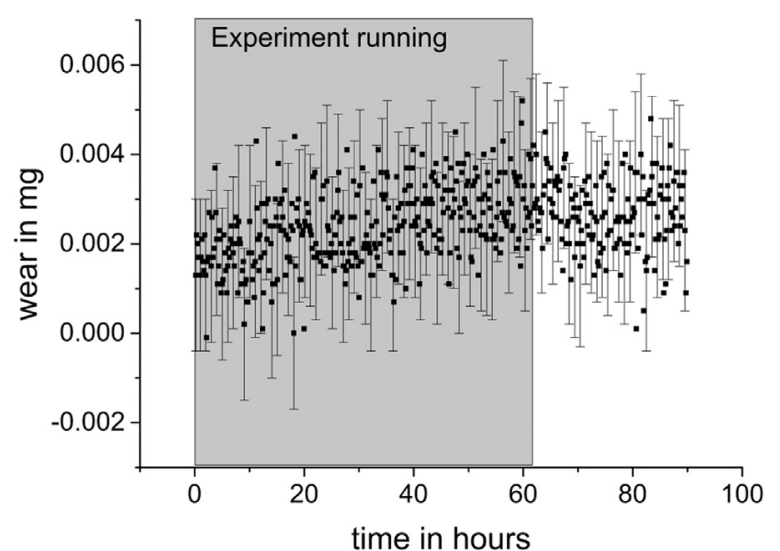

Fig. 2. RNT measurement data plotted over experiment duration. The gray box indicates the experiment duration time.

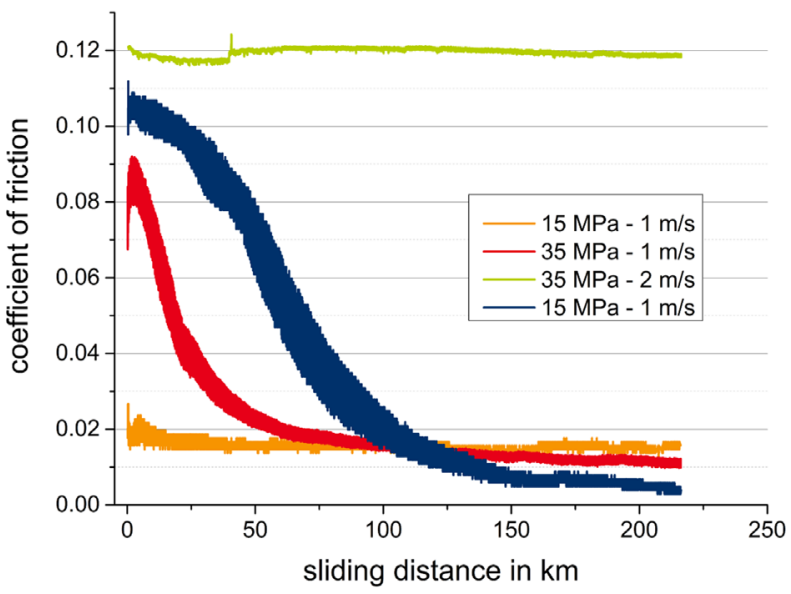

(a) Coefficient of friction over sliding distances for experiments with constant load and speed as indicated in the graph.

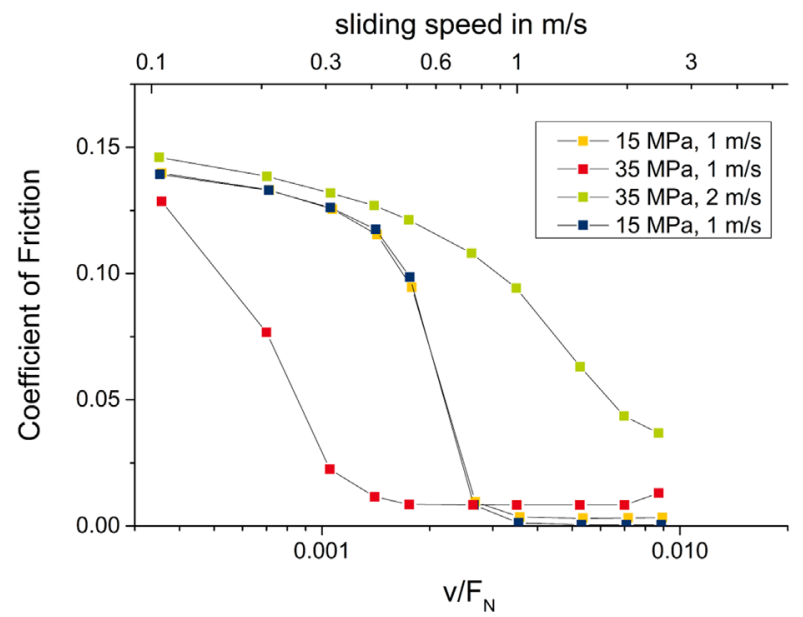

(b) Stribeck curves performed after the running-in at a pressure of $15 \mathrm{MPa}$.

Fig. 3. Running-in and stribeck curves of experiments with constant load and speed, see (a). (For interpretation of the references to color in this figure, the reader is referred to the web version of this article.)

increase in speed) for speeds of $0.6 \mathrm{~m} / \mathrm{s}$ and higher. In contrast, we found the mixed lubrication regime at $2.5 \mathrm{~m} / \mathrm{s}$ after the experi ment, that didn't show a decrease in friction from the CoF of 0.12.

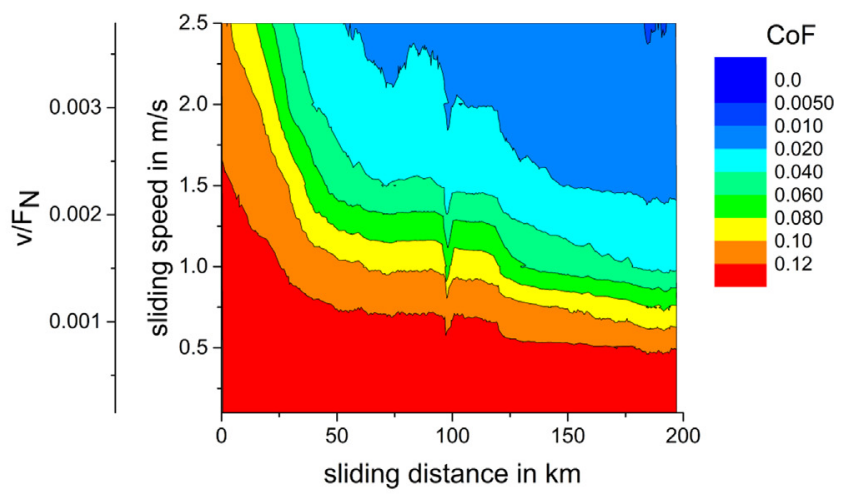

(a) $35 \mathrm{MPa}$.

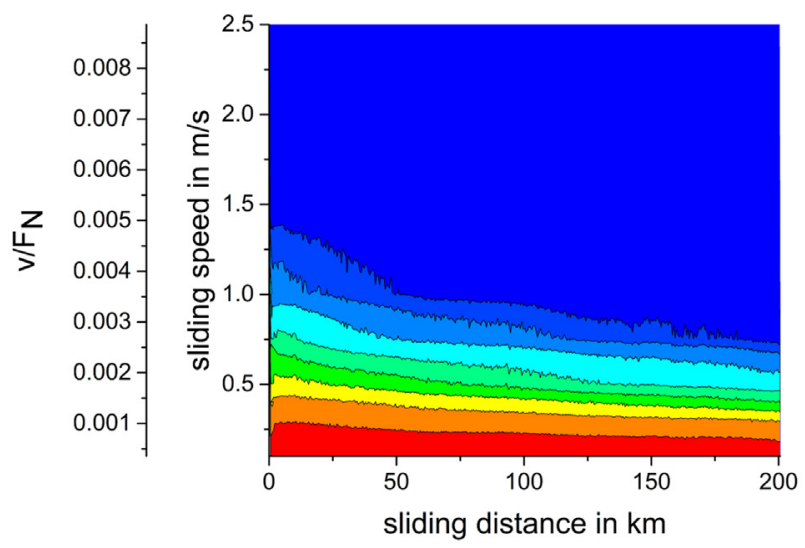

(b) $15 \mathrm{MPa}$

Fig. 4. Friction maps of experiments with constant loads and changes in speed. Color coding valid for both plots.

\subsubsection{Constant load and changes in speed}

Plotting the running in of transient experiments in a conven tional way by showing CoF over time or sliding distance isn't as easily possible as it can be done for a running in at constant load and speed. Therefore, we introduce a time dependent friction map or stribeck map: The sliding speed on the ordinate axis is plotted over the sliding distance on the abscissa. The friction coefficient is color coded or plotted in $\mathrm{z}$ direction. As a second ordinate axis, the reduced Hersey parameter, i.e. sliding speed divided by normal load, is plotted.

Moving the abscissa along the ordinate axis and plotting those values yields a "classic" running in for a constant speed over sliding distance. Plotting a slice in the diagram from data points along an ordinate axis (i.e. at a certain sliding distance) yields a stribeck curve.

Two representative results of transient experiments with con stant load are plotted in Fig. 4.

\subsubsection{Constant speed and changes in load}

As for the previous case of transient experiments with constant load, the friction map can also be plotted for constant speed and varying loads. On the ordinate axis, the load is plotted over the sliding distance and color coding shows the CoF. In Fig. 5, two results of transient experiments under constant speed are plotted.

\subsection{Analytical results}

Before analysis in devices with vacuum, i.e. scanning electron microscopy and XPS, the samples were cleaned with 2 vol \% 

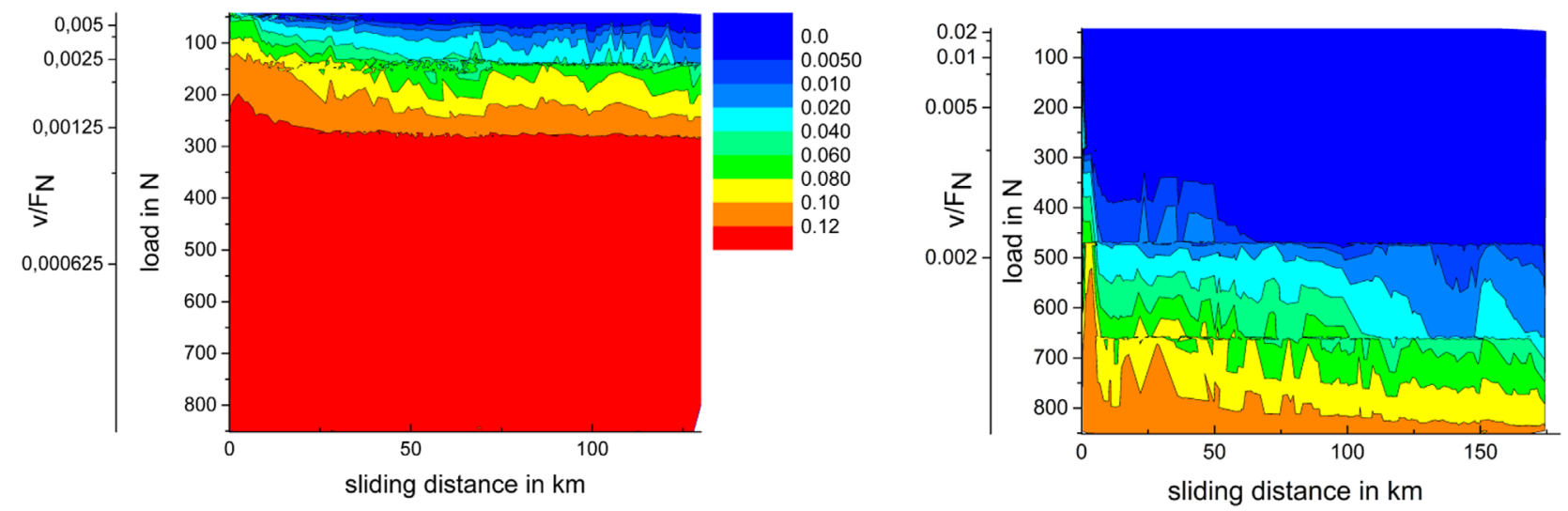

(a) $0.33 \mathrm{~m} / \mathrm{s}$.

(b) $1 \mathrm{~m} / \mathrm{s}$.

Fig. 5. Friction maps of experiments with constant speeds and changes in load. Color coding valid for both plots.

Tickopur R33 cleaner (Dr H Stamm, Berlin, Germany) in ultrasonic bath for 2 minutes, in deionized water for 5 minutes and in iso propyl alcohol for 5 min to remove oil residuals and other con tamination from the surface.

\subsubsection{Subsurface microstructure}

FIB cross sectioning has been done in an unworn disk and pin and in two worn systems with constant load and speed, i.e. $35 \mathrm{MPa}$ and 1 and $2 \mathrm{~m} / \mathrm{s}$. The system at $35 \mathrm{MPa}$ and $1 \mathrm{~m} / \mathrm{s}$ showed a running in behavior, whereas for the system tested at $2 \mathrm{~m} / \mathrm{s}$, no decrease in the coefficient of friction was observed (see Fig. 3(a)). For the system with running in behavior, no significant changes in subsurface microstructure compared to the unworn samples were found neither in the pin nor in the disk. Only minor changes were detected in the subsurface of the disk without running in beha vior. Here, the thickness of the grain refined zone was with approx.
$2.5 \mu \mathrm{m}$ slightly thicker than the one of the machined surface with approx. $1 \mu \mathrm{m}$. This trend also holds true for the pins, where, for the run in system, no subsurface microstructural changes were found compared to the unworn pin, whereas the FIB cross sectioning locally showed some recrystallized grains in the pin of the system without running in behavior.

\subsubsection{Surface chemical analysis}

In many tribological questions, XPS depth profiling can yield useful information on the chemical composition not only at the surface but also in a few or several nanometers depth, thereby showing possible layering or also elements that are hidden at the surface, e.g. due to surface contamination or lubricant residuals. The sputter depth refers to $\mathrm{SiO}_{2}$. Typically, we measure XPS depth profiles by alternating the measurement of photoelectrons and material removal by sputtering with Argon ions.

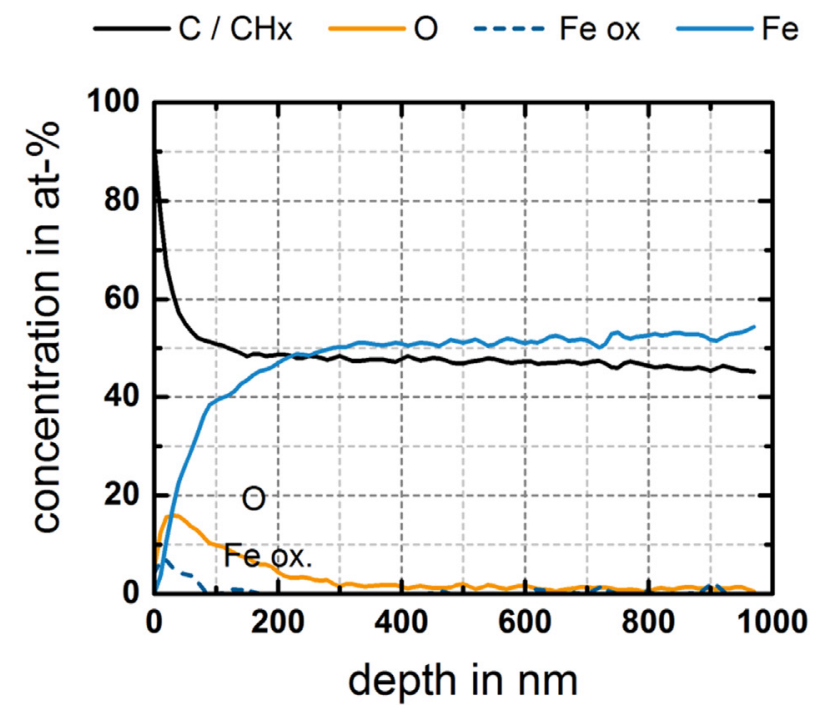

(a) XPS depth profile with alternate
sputtering and measuring.

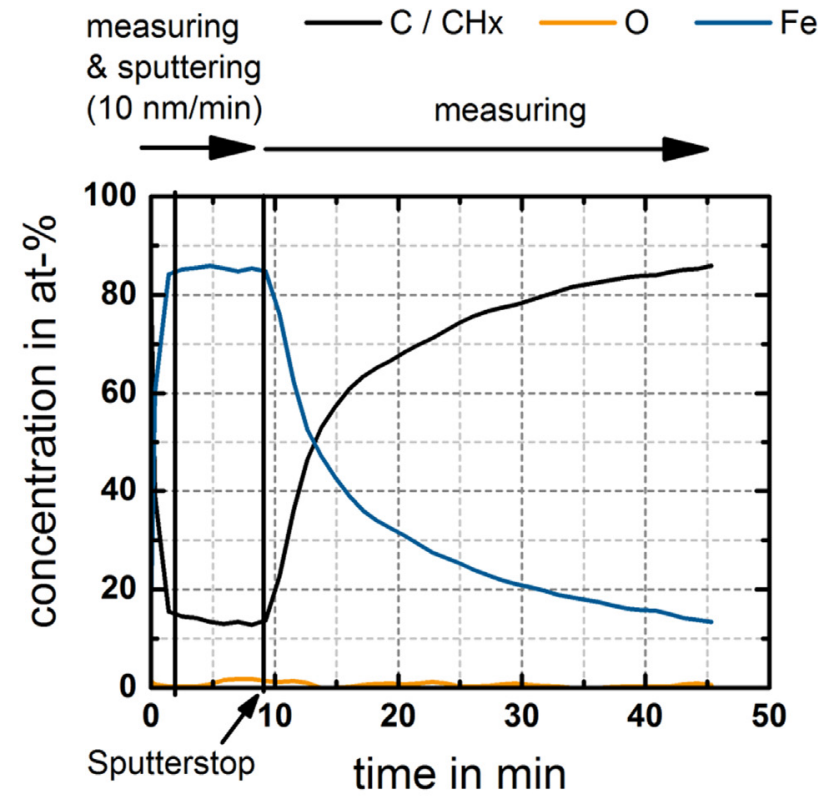

(b) XPS depth profile with continuous sputtering. Sputtering stopped after nine minutes. 
Such an alternating depth profile is shown in Fig. 6(a). We found a carbon content of 50 at \% up to $1, \mu$ m depth which is much higher than expected from the carbon content of the sprayed metal. Interestingly, we observed an increase in carbon content when stopping the sputter process but continuing to measure the photoelectron carbon signal. To get a more realistic measure of the carbon content on the sample, photoelectron measurements were done during sputtering with a sputterrate of $2 \mathrm{kV}$ and $2 \mu \mathrm{A}$. Fig. 6 (b) shows the result of this measurement. The stop of material removal by sputtering yields an increase in carbon content of the surface of more than 80 at \% in $35 \mathrm{~min}$.

Element concentrations in the wear track of the running in ex periment at $35 \mathrm{MPa}$ and $2 \mathrm{~m} / \mathrm{s}$, as shown with a green line in Fig. 3 (a), have been measured by XPS as well. In the case of this disk without running in, no carbon diffusion was found. The performance of a measurement next to the wear track in an unworn area did show carbon diffusion comparable to the result shown in Fig. 6(b).

Due to measurements done on high purity iron samples before and after the measurements described above, contamination of the chamber was excluded. Experiments were done with the described experimental setup and $\mathrm{Cr}$ plated pin on a gray cast iron disk. XPS measurements in this wear track didn't reveal any carbon diffusion.

XPS measurements were repeated on a wear track of a tran sient experiment ( $35 \mathrm{MPa}$, transient speed) and carbon diffusion was found again. To check the influence of surface contamination on the carbon diffusion behavior, the sample was exposed to UV light / ozone in atmosphere for $30 \mathrm{~min}$ to oxidize possible con taminants on the surface. This procedure showed significant re duction from 80 to 20 at \% of carbon contaminants on the surface of an high purity iron sample. But in case of the wear track of the transient experiment, no difference in carbon diffusion was found compared to the measurement before the UV light exposure (Bioforce Nanosciences UV Ozone cleaner).

On the pins of the experiments at $35 \mathrm{MPa}$ and 1 and $2 \mathrm{~m} / \mathrm{s}$, XPS analysis revealed with 1 at \% only traces of $\mathrm{Zn}$ in the first $20 \mathrm{~nm}$ of the pin of the run in system at $35 \mathrm{MPa}$ and $1 \mathrm{~m} / \mathrm{s}$. In contrast, oil residuals, i.e. P, S, Ca and $\mathrm{Zn}$ were found in concentrations of less than 5 at \% in depth of up to $400 \mathrm{~nm}$ on the pin belonging to the experiment without a decrease in the CoF, $35 \mathrm{MPa}$ and $2 \mathrm{~m} / \mathrm{s}$.

\section{Discussion}

\subsection{Wear rates}

Wear rates are classified into "severe" and "mild" wear, with the wear regime of mild wear being characterized by oxidized wear par ticles with approximately 1 to $20 \mu \mathrm{m}$ of size. In contrast, wear particles of experiments in the severe wear regime are metallic and larger than $20 \mu \mathrm{m}$ [16]. The extension of that definition to the ultra low wear regime would be, that wear particles have a size of less than a micron.

Alpas et al. $[17,18]$ define wear regimes with severe (more than $\left.10^{-2} \mathrm{~mm}^{3} / \mathrm{m}\right)$, low $\left(10^{-3}\right.$ to $\left.10^{-4} \mathrm{~mm}^{3} / \mathrm{m}\right)$ and ultra low wear (less than $10^{-4} \mathrm{~mm}^{3} / \mathrm{m}$ ). It has to be noted, that a wear rate of $10^{-4} \mathrm{~mm}^{3} / \mathrm{m}$ is still too high for many applications in modern mechanical systems. In the present system, the pin wear of less than $1 \mathrm{~nm} / \mathrm{h}$ corresponds to $10^{-10} \mathrm{~mm}^{3} / \mathrm{m}$. Also, the disk wear is less than $10^{-7} \mathrm{~mm}^{3} / \mathrm{m}$ ) so that all experiments conducted showed wear rates in the ultra low wear regime. This holds true not only for the RNT experiments, where wear was proven to be ultra low below $0.1 \mu \mathrm{g} / \mathrm{h}$ or less than $1 \mathrm{~nm} / \mathrm{h}$, but also for the experiments without radioactive pins, as the wear track depth for all experi ments showed average wear rates of less than $10 \mathrm{~nm} / \mathrm{h}$. Grinding marks on pins and disks were still visible after $60 \mathrm{~h}$ of sliding, indicating that the results of the RNT technique are realistic. This remarkably low wear rate of the system under the described conditions seems to be an intrinsic property of the tribosystem, i.e. due to the first bodies properties and is not connected to oil ad ditives, as those have hardly reacted with the surface in the case of the run in samples. Oil additive residuals were found on the pin with the CoF of 0.12 for a sliding distance of more than $200 \mathrm{~km}$ (see Fig. 3(a)), which basically means that the oil additives did react due to the constant high frictional energy input into the system, but they didn't contribute to a reduction in friction or wear, either. Additionally, the performance of an experiment with non additivated PAO 8 at $65{ }^{\circ} \mathrm{C}$ (for a viscosity of Polyalphaolefine PAO 8 comparable to 5W30) did yield comparable results in terms of friction and wear. This proves the minor role of oil additives in the present system under the tested conditions.

\subsection{Running in behavior}

In the case of running in analysis at constant load and speed, two out of four experiments show a pronounced running in with a decrease in the coefficient of friction between 80 and $90 \%$ (see Fig. 3(a)). From the coefficient of friction of less than 0.02 for the experiments tested at $1 \mathrm{~m} / \mathrm{s}$, friction behavior of these samples could be considered comparable. A detailed examination by the measurement of stribeck curves at $15 \mathrm{MPa}$ for all experiments yields a more sophisticated result: Although the final coefficient of friction after running in is comparable for three experiments, the stribeck curves measured at samples run in at $15 \mathrm{MPa}$ show a significant difference in transition of the mixed to the EHL regime compared to the samples tested at $35 \mathrm{MPa}$., see Fig. 3(b); yellow and blue lines. As expected from the CoF of 0.12 in the experiment run in at $2 \mathrm{~m} / \mathrm{s}$ (green line in Fig. 3(a)), the corresponding stribeck curve has the highest friction. Interestingly, the stribeck curves of the experiments run in at $15 \mathrm{MPa}$ have an almost identical stri beck curve although the development of the CoF during running in is very different. The stribeck curve of the running in at $35 \mathrm{MPa}$ and $1 \mathrm{~m} / \mathrm{s}$ is the lowest one of the four curves measured. This means, that the initial loading condition during running in sig nificantly influences the friction behavior, but this friction beha vior must not be assessed by the final coefficient of friction during the running in process. It is rather stribeck curves that have to be measured at a comparable condition to evaluate the friction be havior after running in. The influence of the initial loading con ditions on friction and wear behavior (but in this case without the analysis of the friction by stribeck curves) has already been shown by Scherge et al. [9,11] and Volz [19] and is explained by the for mation of a third body $[20,21]$.

In the case of transient experiments with constant load, running in behavior can be analyzed for different speeds, that are tested se quentially in the stribeck curves measured. For the experiment of transient speed and a load of $35 \mathrm{MPa}$ (Fig. 4(a)), the resulting coef ficient of friction as a function of sliding distance is plotted in Fig. 7 (a) for four different speeds. Considering the speed of $2.5 \mathrm{~m} / \mathrm{s}$, run ning in seems completed after $50 \mathrm{~km}$ of sliding distance, whereas no change in friction is found for the sliding speed of $0.3 \mathrm{~m} / \mathrm{s}$. For the intermediate speeds of 0.75 and $1 \mathrm{~m} / \mathrm{s}$, running in isn't completed after $180 \mathrm{~km}$ of sliding distance. The same kind of running in curves can also be extracted for experiments with transient loads, see Fig. 7 (b). Here, friction drops for pressures of 15 and $25 \mathrm{MPa}$ after only a few stribeck curves. Comparable to the speed of $0.3 \mathrm{~m} / \mathrm{s}$ in Fig. 7(a), there is almost no decrease in friction for the pressure of $45 \mathrm{MPa}$, i.e. in the boundary lubrication regime, and a continuous decrease in friction for the pressure of $35 \mathrm{MPa}$.

This result indicates that the emerging third body has some kind of strain rate sensitivity and reacts as a function of speed. Similar results have been published by Rehl [22], who measured the friction in a floating liner engine, showing that the friction reduction is different for different crank angles. 


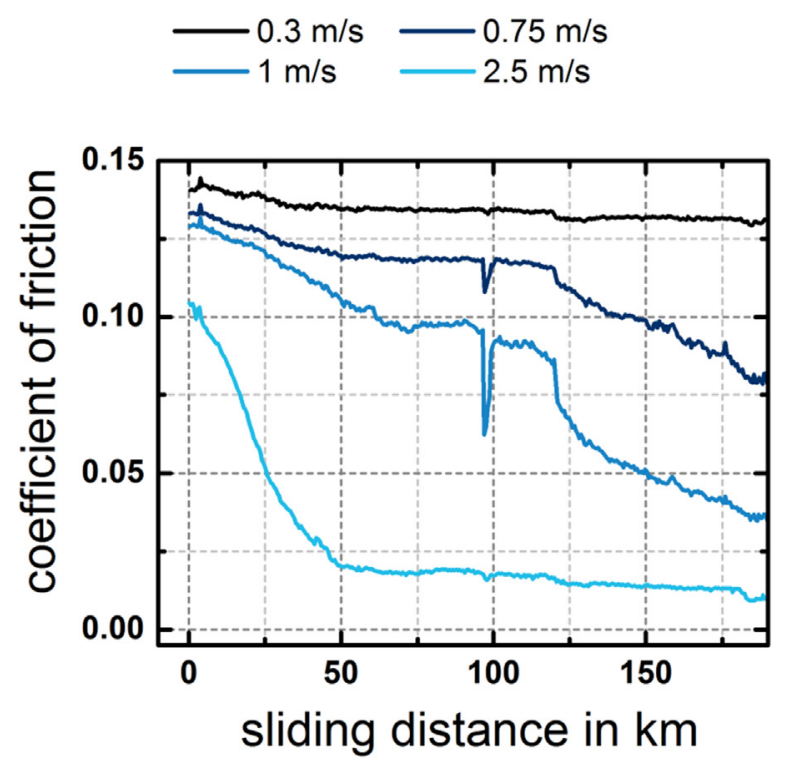

(a) Running-in for selected speeds at 35
MPa extracted from fig. $4(\mathrm{a})$
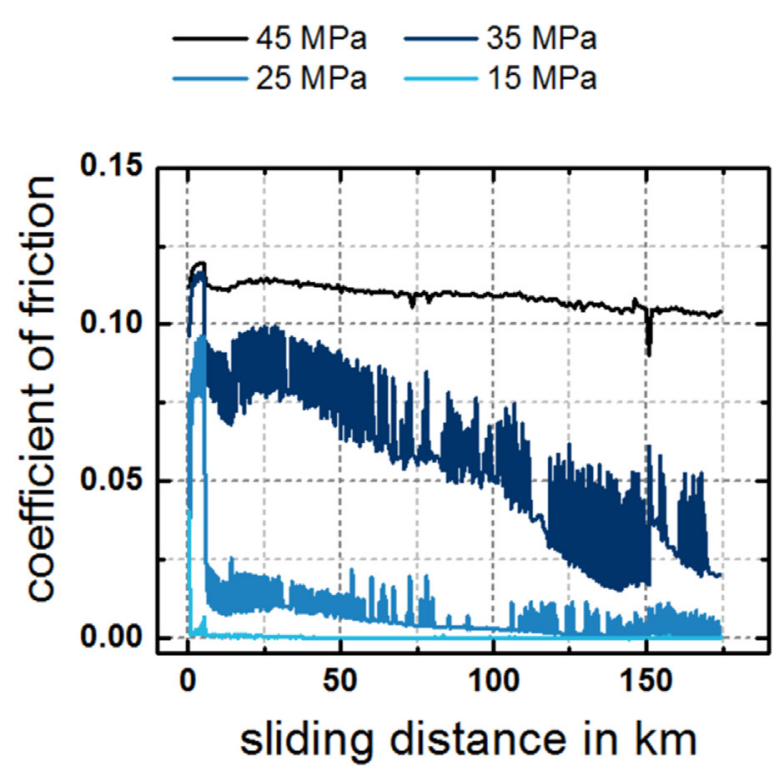

(b) Running-in for selected loads at 1 $\mathrm{m} / \mathrm{s}$ extracted from fig. $5(\mathrm{~b})$.

Fig. 7. Running-in curves of transient experiments.

In Figs. 4(a) and 7(a), there is an abrupt friction decrease at ap prox. $95 \mathrm{~km}$ sliding distance. Detailed analysis shows that this fric tion decrease is lasting 4 transient cycles until the friction of the preceding stribeck curves is reached again. The friction drop is pro nounced only in the mixed lubrication regime. It is not connected to a stop and restart of the experiment. It might be traced to some debris particles, forming a transient third body that is worn off after a few kilometers of sliding distance. As the described drop was only temporary, no ex situ analysis was possible and hence, no explana tion can be offered for the occurrence of the drop.

In the mixed lubrication regime of transient experiments with load variation (Fig. 5 and 7b), the scatter of the data is higher than in boundary lubrication and EHL regime. This is due to the fact, that stribeck curves were measured with increasing as well as with de creasing load. Generally speaking, friction values of the stribeck curves with decreasing load were measured to be significantly higher than the ones measured when coming from the EHL regime. The reason for this behavior remains unclear to the authors. We do not think that it is an artefact of the measurement, because a similar behavior was found by Braun [23] and Olofinjana et al. [24].

The evaluation of the stribeck curves measured at the end of each experiment at $15 \mathrm{MPa}$ allows a comparison of the impact of different test programs on the running in behavior. Friction at the end of the experiment without running in behavior tested at constant pressure and speed of $35 \mathrm{MPa}$ and $2 \mathrm{~m} / \mathrm{s}$ is comparable to the friction measured from an initial stribeck curve and is sig nificantly higher than the friction during the stribeck curve of the run in experiments (Fig. 8). This does not only hold true for the run in experiments at constant load and speed (see Fig. 3(b)), but also for the experiments with transient load or speed.

Comparing the stribeck curves of the run in experiments, no difference in friction as a function of the test procedure, i.e. tran sient conditions or constant load and speed, was found. Stribeck curves of experiments performed with transient speeds show a slightly higher coefficient of friction, but more experiments would be necessary to confirm this trend.

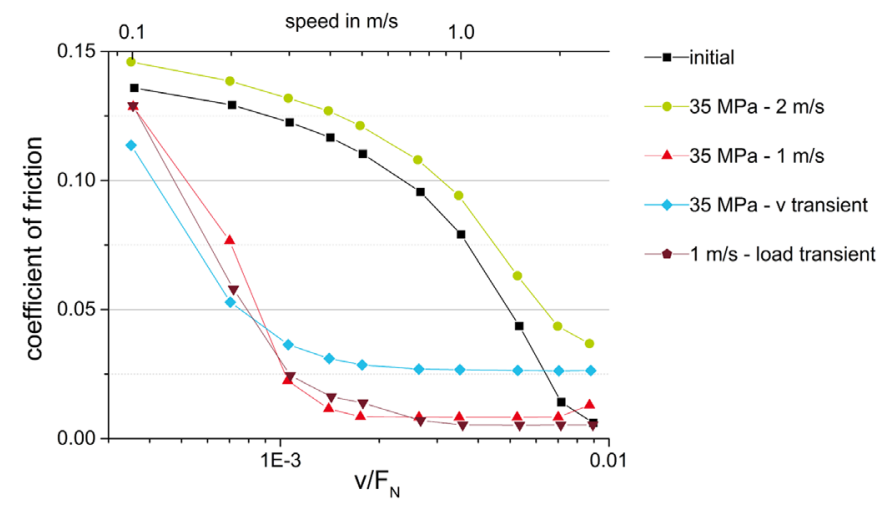

Fig. 8. Stribeck curves measured at the end of selected experiments. An initial stribeck curve is plotted for comparison.

\subsection{Materials analysis}

\subsubsection{Subsurface microstructure}

In many tribological systems, wear is correlated to subsurface plastic deformation [14,25]. In this context, the little amount of subsurface plastic deformation that is indicated by the FIB cross sections correlates to the low wear behavior of the systems.

\subsubsection{XPS depth profiles}

No or only a little amount of elements resulting from oil ad ditives were found by XPS, either at the surface nor after sputter removal of the first two nanometers of material. As discussed above (Section 4.1), the described ultra low wear behavior seems to be an intrinsic property of the system and does not seem to be connected to the lubricant.

The most remarkable effect found by XPS analysis is the carbon diffusion of the thermal spray coating. The carbon diffusion does not seem to be an artefact due to the following reasons:

- Carbon diffusion on the disks have been reproduced on five different disks with up to four different positions on a single disk. 
- Chamber contamination can be excluded as the carbon diffusion has not been found on the pin, nor on an iron reference sample or a worn gray cast iron disk, either.

- Sample contamination can be excluded due to the fact that the carbon diffusion isn't found in the wear track with poor run ning in but next to it in an unworn area. Moreover, measure ments on a pure iron sample before and after cleaning with UV / ozone have shown the effective removal of carbon con taminants from the surface. But this cleaning method didn't have any influence on the carbon diffusion on the coating.

The coincidence of poor running in and missing carbon diffusion might be a first hint to a connection of carbon diffusion, i.e. a carbon film on the surface and the development of low friction. But this conclusion must not be drawn yet, as the carbon diffusion still might not be connected to the low friction values observed. From the XPS signal, it remains unclear if the analyzed carbon is bound as hydro carbon or elementary carbon. Moreover, only one experiment with out running in behavior has been tested so far, meaning that the XPS measurement showing a connection of missing running in and missing carbon diffusion could not be reproduced on a second disk, yet. The influence of the found carbon on the friction behavior of the introduced system is subject to further research.

\section{Conclusions}

For the system of a chromium coated pin against an thermal spray coated disk, we presented a detailed analysis of the run ning in behavior. Different test programs with constant and transient conditions did result in running in behavior. With the analysis of stribeck curves at the end of the experiment, no major differences in friction due to those test programs could be iden tified. A new kind of friction maps was introduced to image the running in under transient conditions. All experiments showed extremely low wear rates that made a further distinction between different testing conditions impossible.

Surface chemical analysis reproducibly showed a carbon diffusion on the surface that seems to be an intrinsic property of the thermal spray layer. One experimental result hints at a connection of the carbon diffusion to friction behavior. This question is subject to fur ther research.

\section{Acknowledgements}

We acknowledge J. Schoenen from Federal Mogul Burscheid and M. Hahn and O. Methner from Daimler AG for supplying $\mathrm{Cr}$ or thermal spray coatings.

\section{References}

[1] M. Hahn, Mikrostrukturelle Veränderungen in der Zylinderlaufbahn von PKW Dieselmotoren aus Grauguss und mittels thermischer Spritzverfahren hergestellter Stahlschichten, (Ph.D. thesis), University Duisburg Essen, Düsseldorf, zugl.: Duisburg, Essen, Univ., Diss., 201, 2, 2013,.

[2] G. Darut, H. Liao, C. Coddet, J. Bordes, M. Diaby, Steel coating application for engine block bores by plasma transferred wire arc spraying process, Surf. Coat. Technol. 268 (2015) 115-122.

[3] M. Hahn, C. Bauer, R. Theissmann, B. Gleising, W. Dudzinski, A. Fischer, The impact of microstructural alterations at spray coated cylinder running surfaces of diesel engines findings from motor and laboratory benchmark tests, Wear 271 (2011) 2599-2609, http://dx.doi.org/10.1016/j.wear.2011.01.090.

[4] A. Rabiei, D. Mumm, J. Hutchinson, R. Schweinfest, M. Ruehle, A. Evans, Microstructure, deformation and cracking characteristics of thermal spray ferrous coatings, Mater. Sci. Eng.: A 269 (1-2) (1999) 152-165.

[5] A. Milanti, V. Matikainen, G. Botelli, H. Koivuluoto, L. Lusvarghi, P. Vuoristo, Microstructure and Sliding wear behavior of fe-based coatings manufactured with hvof and hvaf thermal spray processes, J Therm. Spray Technol. 25 (5) (2016) 1040-1055, http://dx.doi.org/10.1007/s11666-016-0410-z.

[6] M. Hahn, R. Theissmann, B. Gleising, W. Dudzinski, A. Fischer, Microstructural alterations within thermal spray coatings during highly loaded diesel engine tests, Wear 267 (2009) 916-924, http://dx.doi.org/10.1016/j.wear.2008.12.109.

[7] P.J. Blau, How common is the steady-state? The implications of wear transitions for materials selection and design, Wear 332-333 (0) (2015) 1120-1128, http://dx.doi.org/10.1016/j.wear.2014.11.018.

[8] D. Shakhvorostov, L. Jian, E. Nold, G. Beuchle, M. Scherge, Influence of cu grain size on running-in related phenomena, Tribol. Lett. 28 (2007) 307-318, http: //dx.doi.org/10.1007/s11249-007-9274-1.

[9] M. Scherge, D. Shakhvorostov, K. Poehlmann, Fundamental wear mechanism of metals, Wear 255 (1-6) (2003) 395 - 400, in: Proceedings of the 14th International Conference on Wear of Materials. http://dx.doi.org/10.1016/S00431648(03)00273-4

[10] D. Shakhvorostov, B. Gleising, R. Buescher, W. Dudzinski, A. Fischer, M. Scherge, Microstructure of tribologically induced nanolayers produced at ultra-low wear rates, Wear 263 (7-12) (2007) 1259 - 1265, in: Proceedings of the 16th International Conference on Wear of Materials. http://dx.doi.org/10. 1016/j.wear.2007.01.127.

[11] D. Shakhvorostov, K. Pöhlmann, M. Scherge, Zum Einlaufverhalten geschmierter metallischer Kontakte, GfT Jahrestagung, Göttingen (7 2003).

[12] J. Esser, R. Linde, F. Muenchow, Diamantbewehrte Laufschicht fuer Kompressionsringe, MTZ 95 (2004) 582-585.

[13] M. Scherge, K. Poehlmann, A. Gerve, Wear measurement using radionuclidetechnique (RNT), Wear 254 (9) (2003) 801-817.

[14] D. Linsler, F. Schroeckert, M. Scherge, Influence of subsurface plastic deformation on the running-in behavior of a hypoeutectic alsi alloy, Tribology International. http://dx.doi.org/10.1016/j.triboint.2016.01.033.

[15] D. Linsler, T. Schlarb, M. Scherge, Influence of subsurface microstructure on the running-in of an alsi alloy, Wear 332-333, 2015, 926 - 931, proceedings of WoM 2015. http://dx.doi.org/10.1016/j.wear.20105.02.044.

[16] K.C. Ludema, Third bodies in wear models, in: D. Dowson, C.M. Taylor, T. Childs, M. Godet, G. Dalmaz (Eds.), Wear Particles: From the Cradle to the Grave, Elsevier, Amsterdam, 1992, pp. 155 - 160, tribology Series 21.

[17] M. Chen, A. Alpas, Ultra-mild wear of a hypereutectic al-18.5 wt. si alloy, Wear 265 (1-2) (2008) 186-195, http://dx.doi.org/10.1016/j.wear.2007.10.002.

[18] J. Zhang, A. Alpas, Transition between mild and severe wear in aluminium alloys, Acta Mater. 45 (2) (1997) 513-528, http://dx.doi.org/10.1016/ S1359-6454(96)00191-7.

[19] J. Volz, Erstellung optimierter Einlaufprogramme von Dieselmotoren, (Ph.D. thesis), Kernforschungszentrum Karlsruhe, Karlsruhe, kFK 2432 (3 1977).

[20] M. Godet, The third-body approach: a mechanical view of wear, Wear 100 (13) (1984) 437-452, http://dx.doi.org/10.1016/0043-1648(84)90025-5.

[21] M. Godet, Third-bodies in tribology, Wear 136 (1) (1990) 29-45, http://dx.doi. org/10.1016/0043-1648(90)90070-0.

[22] A. Rehl, Reibungs- und Verschleissuntersuchungen am tribologischen System Kolbenring/Aluminium-Silizium-Zylinderlaufbahn, (Ph.D. thesis), KIT, Aachen, karlsruhe, in german (2012).

[23] D. Braun, Groesseneffekte bei strukturierten tribologischen Wirkflaechen, (Ph D. thesis), KIT, Karlsruhe, published online, in german (2015).

[24] B. Olofinjana, C. LorenzoMartin, Oyelayo O. Ajayi, Ezekiel O. Ajayi, Effect of laser surface texturing (LST) on tribochemical films dynamics and friction and wear performance, Wear 332-333 (2015) 1225-1230.

[25] X. Chen, Z. Han, X. Li, K. Lu, Lowering coefficient of friction in cu alloys with stable gradient nanostructures, Sci. Adv. 2 (2016) e1601942. 


\section{Repository KITopen}

Dies ist ein Postprint/begutachtetes Manuskript.

Empfohlene Zitierung:

Linsler, D.; Kümmel, D.; Nold, E.; Dienwiebel, M.

Analysis of the running-in of thermal spray coatings by time-dependent stribeck maps. 2017. Wear, 376-377.

doi: $\underline{10.5445 / / R / 1000070794}$

Zitierung der Originalveröffentlichung:

Linsler, D.; Kümmel, D.; Nold, E.; Dienwiebel, M.

Analysis of the running-in of thermal spray coatings by time-dependent stribeck maps. 2017. Wear, 376-377 (Part B), 1467-1474.

doi:10.1016/j.wear.2017.02.026 